\title{
Polycaprolactone electrospun fiber scaffold loaded with iPSCs-NSCs and ASCs as a novel tissue engineering scaffold for the treatment of spinal cord injury
}

This article was published in the following Dove Press journal:

International Journal of Nanomedicine

XianHu Zhou, ${ }^{1,2 *}$ GuiDong Shi, ${ }^{1,2 *}$ BaoYou Fan, ${ }^{1,2}$ Xin Cheng, ${ }^{1,2}$ XiaoLei Zhang, ${ }^{1,2}$ Xu Wang, ${ }^{1,2}$ Shen Liu, ${ }^{1,2}$ Yan Hao, ${ }^{1,2}$ Zhijian Wei, ${ }^{1,2}$ Lian Yong Wang, ${ }^{3}$ ShiQing Feng ${ }^{1,2}$

'International Science and Technology Cooperation Base of Spinal Cord Injury, Department of Orthopedic Surgery, Tianjin Medical University General Hospital, Tianjin, People's Republic of China; ${ }^{2}$ Tianjin Neurological Institute, Key Laboratory of Post-Neuroinjury Neuro-repair and Regeneration in Central Nervous System, Ministry of Education and Tianjin City, Tianjin, People's Republic of China; ${ }^{3}$ Key Laboratory of Bioactive Materials, Ministry of Education, College of Life Sciences, Nankai University, Tianjin, People's Republic of China

*These authors contributed equally to this work

Correspondence: ShiQing Feng Department of Orthopedics, Tianjin Medical University General Hospital, I54 Anshan Road, Heping District, Tianjin, People's Republic of China $\mathrm{Tel} / \mathrm{fax}+86$ I39 20286292

Email sqfeng@tmu.edu.cn

LianYong Wang

Key Laboratory of Bioactive Materials, Ministry of Education, College of Life Sciences, Nankai University, Weijin Road, Nankai District, Tianjin 30007I, People's Republic of China

Tel +86 I37 02 I0 6786

Email wly@nankai.edu.cn
Background: Spinal cord injury (SCI) is a traumatic disease of the central nervous system, accompanied with high incidence and high disability rate. Tissue engineering scaffold can be used as therapeutic systems to provide effective repair for SCI.

Purpose: In this study, a novel tissue engineering scaffold has been synthesized in order to explore the effect of nerve repair on SCI.

Patients and methods: Polycaprolactone (PCL) scaffolds loaded with actived Schwann cells (ASCs) and induced pluripotent stem cells -derived neural stem cells (iPSC-NSCs), a combined cell transplantation strategy, were prepared and characterized. The cell-loaded PCL scaffolds were further utilized for the treatment of SCI in vivo. Histological observation, behavioral evaluation, Western-blot and qRT-PCR were used to investigate the nerve repair of Wistar rats after scaffold transplantation.

Results: The iPSCs displayed similar characteristics to embryonic stem cells and were efficiently differentiated into neural stem cells in vitro. The obtained PCL scaffolds were $\sim 0.5 \mathrm{~mm}$ in thickness with biocompatibility and biodegradability. SEM results indicated that the ASCs and (or) iPS-NSCs grew well on PCL scaffolds. Moreover, transplantation reduced the volume of lesion cavity and improved locomotor recovery of rats. In addition, the degree of spinal cord recovery and remodeling maybe closely related to nerve growth factor and glial cell-derived neurotrophic factor. In summary, our results demonstrated that tissue engineering scaffold treatment could increase tissue remodeling and could promote motor function recovery in a transection SCI model.

Conclusion: This study provides preliminary evidence for using tissue engineering scaffold as a clinically viable treatment for SCI in the future.

Keywords: induced pluripotent stem cells, polycaprolactone, spinal cord injury

\section{Introduction}

Spinal cord injury (SCI) is a serious medical condition that causes significant problem in the medical community. ${ }^{1-3}$ Due to the disability and multiple complications caused by the SCI, tens of thousands of people are afflicted each year, and this has a devastating impact on the well-being and financial stabilities of patients and their families. ${ }^{4}$ However, there is still no definitive repair methods for SCI, especially, complete SCI. The main problems faced by nerve repair are lack of self-repair and neurotrophic factors, primary and secondary neuronal apoptosis, and factors that inhibit the regeneration of axons locally. ${ }^{5,6}$ Effective repair can not only greatly improve the quality of life for patients with SCI but also relieve their psychological and economic burden. Therefore, improving 
the quality of life has become the focus and primary goal of researchers. In recent years, drugs and pharmacology, surgical repair of nerve defects, neurotrophic factors, biological activity material, tissue engineering, and genetic engineering studies became mainstream research methods in the field of SCI. ${ }^{7}$

The microenvironment of the spinal cord changes immediately after a mechanical crushing or stretching of the spinal cord. ${ }^{8-10}$ Axonal damage and cell membrane disruption cause glia loss in the primary injury of the spinal cord. ${ }^{11}$ Then, a cascade of molecular and signaling pathways initiate a series of secondary injuries to the spinal cord. Inflammatory cells such as microglia, macrophages, and neutrophils infiltrate the injury site as a result of disruption of the blood-spinal cord barrier during the secondary injuries. ${ }^{12}$ Secondary injury cascade and oxidative stress cause more neuronal and glial deaths. ${ }^{13}$ Therefore, much attention has been directed at new therapeutic strategies for SCI. Bioactive materials and cell therapy have been recognized as major treatment methods for SCI in recent years. ${ }^{14,15}$

Induced pluripotent stem cells (iPSCs) have become the focus in the field of stem cell research and have wide application prospects in many fields such as autologous cell transplantation, tissue engineering research, and drug development. ${ }^{16-18}$ IPSCs provide a cell source that has characteristics of embryonic stem cells but are associated with fewer moral and ethical issues. In 2007, Takahashi et al successfully reprogrammed human cells into iPSCs for the first time, which made these cells an ideal autologous transplantation cell resource. ${ }^{19}$ Recently, in the Rikagaku Kenkyūjo Center of Japan, iPSCs have been used in clinical research. The Takahashi group utilized retinal pigment epithelium cells derived from iPSCs to treat age related macular degeneration. To this day, no complications have been reported from this surgery. ${ }^{20}$ Due to the gradual improvement of the safety and efficiency in iPSCs reprogramming, it has a broader application in regenerative medicine and cell transplantation.

Schwann cells (SCs) are glial cells of the peripheral nerves. ${ }^{21,22}$ It is one of the most important seed cells in the repair of SCI due to the ability to secrete a variety of nutritional factors and extracellular matrix that can improve the local microenvironment. Waller's degeneration occurs immediately after peripheral nerve injury. Activated SCs (ASCs) proliferate and migrate to the lesion site, co-phagocytose damaged axonal myelin with macrophages and guide the regeneration, elongation, and myelination of axons. ${ }^{23}$ Previous studies have shown that, after transplantation of SCs, the host's endogenous P75+ cells are activated and infiltrated into the lesion site, indicating that endogenous SCs may play an important role in the repair after cell transplantation. ${ }^{24}$ In addition, the neurotrophic factors and cell adhesion molecules secreted by ASCs can also induce axon myelination and neuronal survival. ${ }^{25}$ While several studies have shown that single SC repair of SCI is still limited, researchers try to transplant it with other stem cells in order to achieve better effects. ${ }^{26-28}$ Coculture of SCs with neural stem cells (NSCs) can remarkably increase the proportion of neuron differentiation and effectively improve the recovery of nerve endings. ${ }^{29}$

Polycaprolactone (PCL) is an aliphatic, biodegradable, nontoxic polyester with good mechanical properties. Due to its deficient biological activity and hydrophobicity it is widely used in absorbable suture materials, surgical dressing, and internal fixations. ${ }^{30-32}$ It is also approved by the United States Food and Drug Administration (FDA). The popularity of PCL in these applications can be attributed to its biocompatibility, biodegradability, and high processability. ${ }^{33}$ Its longer degradation cycle allows it to be used as a carrier for cell transplantation and integrate the seed cells into host tissues. Our previous study investigated the biocompatibility of electrospinning PCL scaffolds and coculture system, which consisted of NSCs and ASCs. ${ }^{34}$ ASCs and iPSCs-derived NSCs (iPSCs-NSCs) can grow well on these electrospinning PCL scaffolds, and ASCs could distribute along the fibers. However, the extraction of human NSCs is ethically unacceptable and, therefore, finding a viable and safe tissue engineering strategy is the common research goal in this field.

In this study, we used the electrospinning method to fabricate nanofibrous PCL scaffolds. We reprogrammed human umbilical cord blood (hUCB) cells into iPSCs and then induced it to differentiate into NSCs. Finally, we transplanted the engineered PCL scaffolds containing ASCs and iPSCs-NSCs to the site of injury of the rats.

\section{Materials and methods}

\section{Ethics}

All animal handling procedures and experimental protocols were approved by the Animal Care and Use Committee of Tianjin Medical University. All procedures involving animals were consistent with the ethical standards set by the abovementioned institutions. Pregnant Institute-of-Cancer-Research (ICR) mice (100 $\pm 10 \mathrm{~g})$ and Wistar rats (230-250 g) were obtained from Laboratory Animal Center of Chinese People's Liberation Army General Hospital (Beijing, China, Approval Number: SCXK2012-0004). HUCB was obtained from Tianjin First Central Hospital. The Ethical Committee of Tianjin Medical University General Hospital approved this study. 


\section{Preparation and characterization of cells} Mouse embryonic fibroblast (MEF)

Isolation, culture, and inactivation of ICR MEF were performed as described previously. ${ }^{35}$

\section{IPSCs}

Fresh hUCB samples were obtained from the Tianjin First Central Hospital after full term delivery with written informed consent of the mother. The umbilical cord blood mononuclear cells were separated from the hUCB using Ficoll-Paque PLUS (Solarbio, Beijing, China). Cells $\left(\sim 5 \times 10^{4}\right)$ were seeded in a 6-well plate with a culture medium 1640 (Thermo Fisher Scientific, Waltham, MA USA) containing $1 \%$ penicillinstreptomycin (Thermo Fisher Scientific) and 10\% FBS (Thermo Fisher Scientific). After $\sim 24$ hours, the mononuclear cells were treated with the lentivirus (EMD Millipore, Billerica, MA, USA) with addition of polybrene $(1 \mu \mathrm{g} / \mu \mathrm{L})$ (EMD Millipore) and subjected to further incubation for 24-48 hours. Next day, after the cells were washed thrice with $1 \times$ PBS (Solarbio), $2 \mathrm{~mL}$ of fresh medium was added. Four days after viral transduction, inactivated ICR MEF feeder layers were prepared to support the cells, followed by further incubation with daily change of the human iPSCs medium (Thermo Fisher Scientific). IPSCs-like colonies were selected as a clone at 15-18 days. Passage of iPSCs colonies with stem cell passaging tool (Thermo Fisher Scientific).

\section{IPSCs-derived NSCs}

When colonies reached $\sim 80 \%$ confluency, medium in the well was aspirated and neural induction medium was added according to previous protocol. ${ }^{36}$ Briefly, after treatment with Tryple, iPSCs were detached from 6-well plates, and the cells were plated at $5 \times 10^{5}$ cells per well to generate embryoid bodies (EBs) cultured with EBs medium (1\% GlutaMAX, $1 \% \mathrm{~N} 2,2 \% \mathrm{~B} 27,1 \%$ penicillin-streptomycin, $1.25 \mu \mathrm{M}$ dorsomorphin, and neurobasal medium). After treatment with Accutase ${ }^{\circledR}$, the EBs were digested into single cells and then plated at a density of $2 \times 10^{6}$ cells per T75 with NSCs medium. This medium was comprised of DMEM/F12, 2\% B27 supplement, 1\% penicillin-streptomycin, epidermal growth factor (20 ng/mL) (all from Thermo Fisher Scientific), and fibroblast growth factor $(20 \mathrm{ng} / \mathrm{mL})$.

\section{ASCs}

ASCs were isolated from the sciatic nerves of adult Wistar rats as described previously. ${ }^{37}$ Briefly, following the removal of the connective tissues, epineurium, and blood vessels, sciatic nerve explants were cut into $\sim 1 \mathrm{~mm}^{3}$ and incubated for 40 minutes in $5 \mathrm{~mL} 0.05 \%$ collagenase (Solarbio). Then, the sciatic nerve explants were washed thrice in PBS and placed into T75 containing DMEM/F12, 10\% FBS, and 1\% penicillin-streptomycin.

\section{Immunostaining}

For the antibody staining, cells fixed with $4 \%$ paraformaldehyde were washed thrice with PBS and then were permeabilized with $0.5 \%$ Triton X-100. After being blocked with $5 \%$ normal goat serum for 40 minutes at room temperature, cells were incubated with primary antibody at $4^{\circ} \mathrm{C}$ for 24 hours. IPSCs were evaluated by immunostaining of Oct4, Sox2, Nanog, SSEA4, and TRA-1-60. ASCs were investigated by immunostaining of S100, and NSCs were examined by Tuj1, O4, and GFAP. The nucleus was stained with DAPI (all from Abcam, Cambridge, MA, USA). A summary of antibodies mentioned above is provided in Table 1. Cells were observed under an inverted fluorescence microscope (Leica, Wetzlar, Germany).

\section{Preparation of PCL electrospun fiber membrane}

A total of $15 \mathrm{wt} \%$ poly(e-caprolactone) was dissolved in the solution (dimethylformamide and acetone, 7:3) at a constant temperature of $80^{\circ} \mathrm{C}$. This solution was used to generate a degradable PCL electrospun fiber membrane with a pore diameter of $<10 \mu \mathrm{m}$ and $\sim 0.5 \mathrm{~mm}$ in thickness. After being dried in a vacuum dryer at $30^{\circ} \mathrm{C}$ for 72 hours, the membrane was cut into $4 \times 4 \mathrm{~mm}$ pieces, which were put up with cobalt 60 irradiation for sterilization. Before cell seeding, the PCL

Table I Primary antibodies

\begin{tabular}{|c|c|c|c|c|}
\hline Antibodies & Species & Type & Dilution & Source \\
\hline Oct4 & Rabbit & Monoclonal IgG & $1: 1,000$ & Abcam \\
\hline Sox2 & Rabbit & Polyclonal lgG & $1: 1,000$ & Abcam \\
\hline Nanog & Rabbit & Polyclonal IgG & $\mathrm{I}: \mathrm{I}, 000$ & Abcam \\
\hline SSEA4 & Mouse & Monoclonal lgG & $\mathrm{I}: 1,000$ & Abcam \\
\hline TRA-I-60 & Mouse & Monoclonal IgG & $1: 1,000$ & Abcam \\
\hline SI00 & Rabbit & Monoclonal IgG & $1: 100$ & Abcam \\
\hline Tujl & Rabbit & Polyclonal lgG & $\mathrm{I}: 500$ & Abcam \\
\hline O4 & Mouse & Monoclonal IgM & $1: 100$ & $\begin{array}{l}\text { R\&D System, } \\
\text { Minneapolis, } \\
\text { MN, USA }\end{array}$ \\
\hline GFAP & Goat & Polyclonal lgG & $1: 1,000$ & Abcam \\
\hline NT3 & Rabbit & Polyclonal lgG & $1: 1,000$ & Abcam \\
\hline GDNF & Rabbit & Monoclonal lgG & $1: 1,000$ & Abcam \\
\hline NGF & Rabbit & Monoclonal IgG & $\mathrm{I}: 1,000$ & Abcam \\
\hline
\end{tabular}

Abbreviations: GDNF, glial cell-derived neurotrophic factor; GFAP, glial fibrillary acidic protein; Nanog, homeobox protein NANOG; NGF, nerve growth factor; NT3, neurotrophin 3; O4, oligodendrocyte marker O4; Oct4, octamer-binding transcription factor 4; S-100, S100 protein; SSEA4, stage specific embryonic antigen 4; Sox2, SRY (sex determining region Y)-box 2; TRA, terato-related antigen; Tujl, Class III $\beta$-tubulin. 
electrospun fiber membrane was sterilized with $70 \%$ alcohol, and then washed thrice with PBS. A 5- $\mu \mathrm{L}$ aliquot of medium containing ASCs and/or NSCs was then slowly injected ints each scaffold (a total of $5 \times 10^{5}$ cells/scaffold).

\section{Spinal cord transection and transplantation}

Based on the different treatments, 60 Wistar rats were divided into four experimental groups, in order to minimize the sacrifice and suffering of animals, we refer to previous experiments and cancel the sham operation group. ${ }^{28}$ The control group is Group 1.

Group 1: PCL scaffolds group ( $\mathrm{n}=15)$

Group 2: PCL scaffolds+ASCs group $(\mathrm{n}=15)$

Group 3: PCL scaffolds+NSCs group $(\mathrm{n}=15)$

Group 4: PCL scaffolds+ASCs+NSCs group $(\mathrm{n}=15)$.

Adult female Wistar rats (230-250 g) were used for spinal cord transection. Animals were acclimatized for at least one weeks before surgery. Before surgery, all rats subjected to SCI were deeply anesthetized with isoflurane. Following laminectomy at the T10 vertebral level, a 2-mm segment of spinal cord was completely removed. Then the lesion gap was covered with tissue engineered scaffolds as previously described.$^{38}$ After the surgical incision closure, the rats received intensive postoperative care, including manual emiction twice daily till their automatic micturition function reestablished. Penicillin $(40,000 \mathrm{U} / \mathrm{kg} / \mathrm{d})$ was intramuscular injected for 5 days to prevent any possible infections.

\section{Immunohistochemistry and histological assessment}

Eight weeks after transplantation, all animals were anesthetized with isoflurane, after perfused intracardially with $250 \mathrm{~mL}$ of saline followed by $250 \mathrm{~mL}$ of $4 \%$ paraformaldehyde in PBS. Six spinal cord tissue samples in each group were prepared as paraffin sagittal sections at $10 \mu \mathrm{m}$ thickness, the rest were stored at $-80^{\circ} \mathrm{C}$. Paraffin sections were stained with hematoxylin-eosin (H\&E) (Solarbio), as described previously. ${ }^{39}$ Finally, the stained sections were observed under the microscope (Leica).

\section{Assessment of locomotor recovery}

After surgery, hindlimb function of the rats was evaluated with the Basso, Beattie, and Bresnahan (BBB) open field locomotor test every week. ${ }^{40}$ Score ranges from 0 (no hindlimb movement) to 21 (normal hindlimb movement). Two independent researchers blinded to these different experimental treatments determined the BBB scores.

\section{Western blot analysis}

After weighed and minced with eye scissors on ice, the samples were homogenized in lysis buffer, centrifuged at 12,000 rpm, $4^{\circ} \mathrm{C}$ for 10 minutes. Then, the samples were subjected to SDS-PAGE. Next, the protein was electrophoretically transferred to a polyvinylidene fluoride filter membrane. The membrane was blocked with $4 \%$ nonfat dry milk and incubated with primary antibodies against neurotrophin 3 (NT3), glial cell-derived neurotrophic factor (GDNF), and nerve growth factor (NGF) at $4{ }^{\circ} \mathrm{C}$ overnight. Next day, the membranes were washed thrice with tris buffered saline tween and were incubated for more than 2 hours at room temperature with second antibodies. The proteins were visualized with an enhanced chemiluminescence system (ECL; R\&D system, Minneapolis, MN, USA). The scanned images were then semi-quantitated using the Quantity One software and normalized with $\beta$-actin.

\section{Quantitative real-time PCR}

Total RNA was extracted from spinal cord tissues using a TRIzol reagent (Thermo Fisher Scientific) according to the manufacturer's instructions. One microgram of total RNA per sample was reverse transcribed using a Reverse Transcription Kit (TaKaRa, Shiga Perfecture, Japan). Quantitative real-time RT-PCR was performed on a LightCycler $^{\circledR} 480$ Real-Time PCR System (Hoffman-La Roche Ltd., Basel, Switzerland) using SYBR Green (TaKaRa). $\beta$-actin acted as internal control. All samples were analyzed in duplicate, and then the average value of the duplicates was used for quantification. The primers are listed in Table 2.

\section{Statistical analysis}

The Prism statistical software (v6.01; GraphPad Software, Inc., La Jolla, CA, USA) was employed for data analysis. Statistical differences between two groups were analyzed using Student's $t$-test. One-way ANOVA analysis was used to compare the mean BBB scores in different groups. All data were presented as mean \pm standard error of mean. $P<0.05$ was considered a statistically significant difference.

\section{Results}

\section{Isolation of mononuclear cells for iPSCs generation from cord blood}

After adding Ficoll-Paque PLUS, cord blood was separated into four layers, namely plasma, lymphocyte, mononuclear cells, and red cells layers. The entire reprogramming process needs about 25 days (Figure 1A). Before adding the lentivirus, the prepared MEF should be frozen in advance (Figure 1Ba). Eighteen days after the isolation of mononuclear cells and 
Table 2 Information of primer sequences

\begin{tabular}{|l|l|l|l|}
\hline Gene & Forward primer $\mathbf{5}^{\prime}$ to $\mathbf{3}^{\prime}$ & Reverse primer $\mathbf{5}^{\prime}$ to $\mathbf{3}^{\prime}$ & $\begin{array}{l}\text { Annealing temperature } \\
\left({ }^{\circ} \mathbf{C}\right)\end{array}$ \\
\hline$\beta$-actin & AGCGTGGCTACAGCTTCACC & AAGTCTAGGGCAACATAGCACAGC & 57.5 \\
\hline NT3 & ACGGCAACAGAGACGCTACAATTC & TCCTCGGTGACTCTTATGCTCTGC & 59.2 \\
\hline NGF & CAACAGGACTCACAGGAGCAAGC & GATGTCCGTGGCTGTGGTCTTATC & 58.4 \\
\hline GDNF & AAGGTCGCAGAGGCCAGAGG & CCGCTTCACAGGAACCGCTAC & 53.9 \\
\hline
\end{tabular}

Abbreviations: GDNF, glial cell-derived neurotrophic factor; NGF, nerve growth factor; NT3, neurotrophin 3.
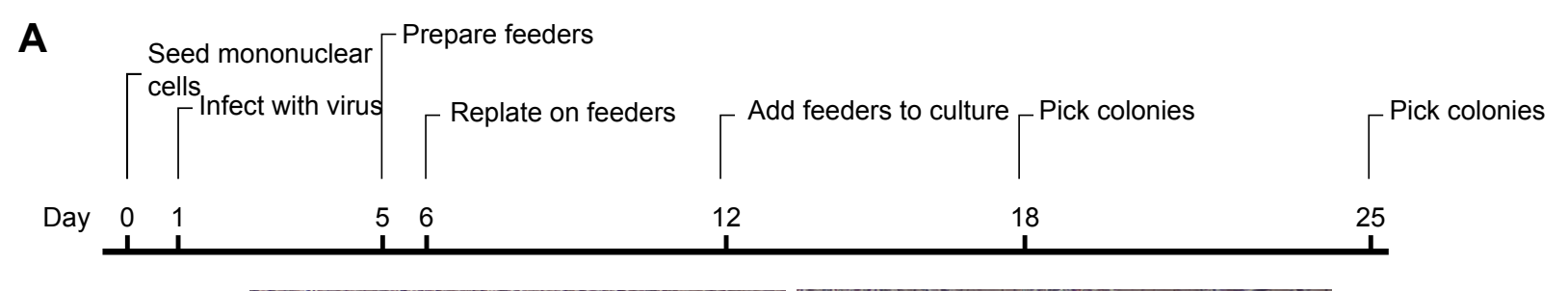

B
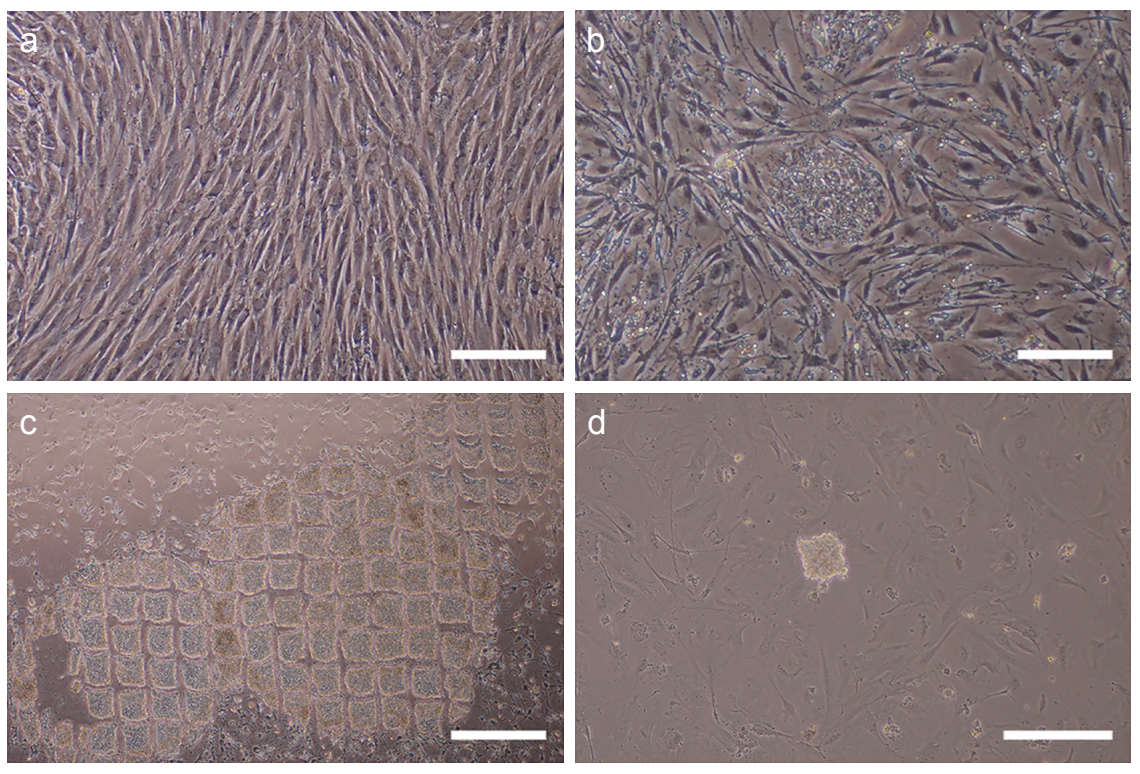

C
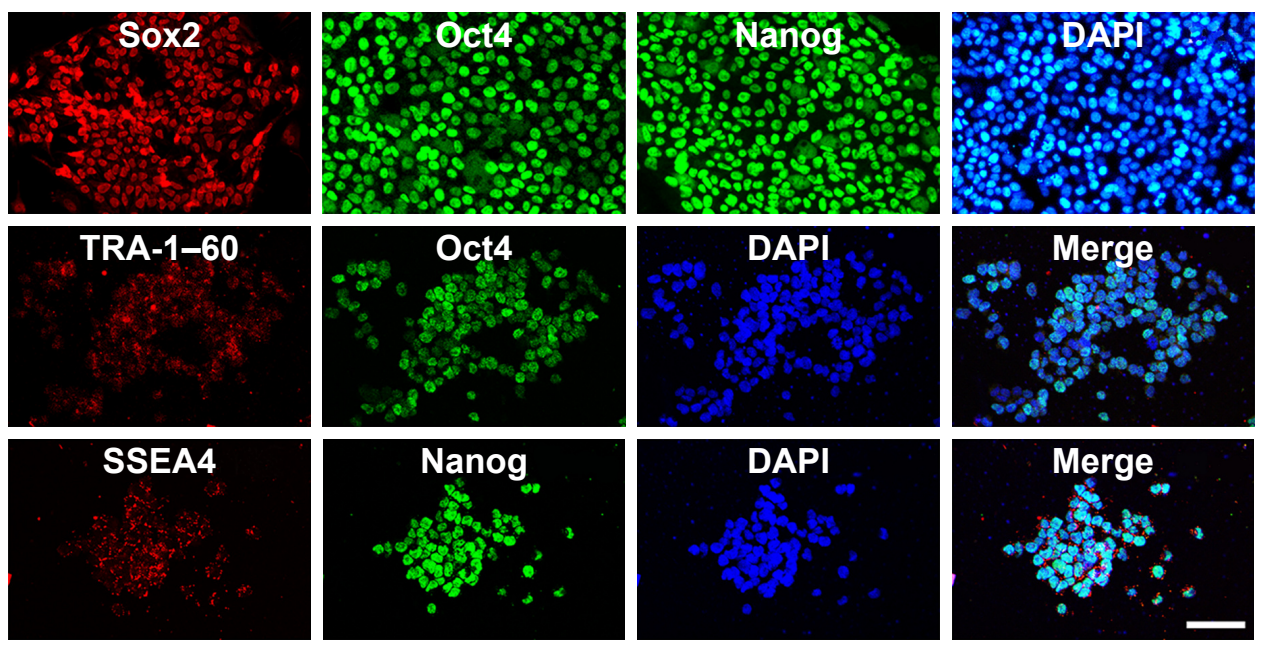

Figure I Preparation and characterization of iPSCs.

Notes: (A) A time-course schema of reprogramming hUCB mononuclear cells. (B) Preparation of MEF (a), and passage of iPSCs colonies (b) with stem cell passaging tool (c) to adapt them to multicelled growth conditions (d). (C) Immunofluorescent staining images of Sox2, SSEA4, TRA-I-60 (red), Oct4, Nanog (green), and DAPI (blue) of iPSCs. Scale bar $=100 \mu \mathrm{m}$.

Abbreviations: DAPI, 4',6-Diamidino-2-Phenylindole; hUCB, human umbilical cord blood; iPSCs, induced pluripotent stem cells; MEF, mice embryonic fibroblast; Nanog, homeobox protein NANOG; Oct4, octamer-binding transcription factor 4; SSEA4, stage specific embryonic antigen 4; Sox2, SRY (sex determining region Y)-box 2; TRA, terato-related antigen. 
virus infection, small iPSCs colonies may start to appear (Figure 1Bb). Passage of iPSCs colonies with stem cell passaging tool was used to adapt them to multicelled growth conditions (Figure 1Bc and d). Immunostaining demonstrated that the iPSCs robustly expressed undifferentiated cell markers Sox2, Oct4, Nanog, SSEA4, and TRA-1-60 (Figure 1C). As previously reported, we used four transcription factors (Oct4, Sox2, Klf4, and c-Myc) to induce iPSCs, and the human iPSCs colonies formed in our study displayed characteristics similar to human embryonic stem cells.

\section{Generation and characterization of ASCs and iPSCs-NSCs}

One week after the addition of EBs medium, the homogeneous EBs can be seen in the 6-well plate (Figure 2Aa). The EBs were cultured for another week to allow the formation of self-organized neuroepithelium that will give rise to NSCs (Figure $2 \mathrm{Ab}$ and $\mathrm{c}$ ). The NSCs displayed positive Tuj1, GFAP, and $\mathrm{O} 4$ staining (Figure 2B). The above immunostaining results indicate that the induced NSCs have the ability to differentiate into oligodendrocytes, neurons, and astrocytes. In addition, ASCs were extracted from Wistar rats. At 9 days post-isolation of the cells, they proliferated and covered the entire T75 bottom (Figure 2Ca). Based on immunocytochemical staining, the ASCs express the peripheroneural markers S100 (Figure $2 \mathrm{Cb}-\mathrm{d}$ ). Our previous studies have demonstrated that ASCs have better adhesion and proliferation than normal SCs. ${ }^{41}$ Therefore, in this study, ASCs were used instead of normal SCs in tissue engineering.

\section{Features of the cocultured cells in PCL scaffold}

PCL scaffolds used in this study were prepared by electrospinning technique, and the membranes were designed by a punch process: $0.8 \mathrm{~cm}^{2}$. Fibers were arranged randomly. Electron microscopy indicated that the pore diameter was $<10 \mu \mathrm{m}$ (Figure 3A). The morphometric scanning electron microscope results indicated that the ASCs and/or iPSCs-NSCs grew well on PCL electrospun fiber membrane (Figure 3B). These results indicated the great biocompatibility of PCL scaffold.

\section{Tissue remodeling in injured spinal cord}

The histopathological manifestations in injured spinal tissues at 8 weeks post-operation were analyzed. Grafts integrated better with the host tissues of the spinal cord by covering rostral and caudal stumps in the cell-containing PCL scaffold groups than those compared with the PCL scaffold group
(Figure 4A and 4B). In Group 1, atrophic neuronal cells, larger cavities, and cell infiltration were observed in the spinal cord lesion. H\&E staining 8 weeks after SCI showed that cell transplantation reduced the cavity and some cell infiltration in the spinal cord. Eight weeks after SCI, in Group 2 and Group 3, some cell infiltration was observed in the injured spinal cord. In Group 4, there are more infiltrating cells and fewer cavities than Group 2 and Group 3 (Figure 4Ca-d). This indicates that transplantation of cells and PCL scaffolds can improve the remodeling of injured spinal cord tissue.

\section{Behavioral outcome at 8 weeks post-injury} Before and after tissue engineering scaffold transplantation, behavioral analysis was performed to rate open-field locomotion by BBB scale. The hindlimbs of all of groups of Wistar rats were completely paralyzed after the T10 spinal cord tissue was transected. One week after surgery, all surgical treatments of the animals showed some slight recovery. Thereafter, animals treated with PCL scaffolds alone showed smaller improvements while rats treated with PCL scaffolds+ASCs+NSCs showed faster and better, but nonsignificant, recovery. At 8 weeks post-surgery, the BBB score of PCL scaffolds+ASCs+NSCs group reached a level of 12 , indicating tissue engineering scaffolds that contain ASCs and NSCs may have a positive influence on motor recovery (Figure 5).

\section{Analysis of NGF and neurotrophic factors}

To probe the possible function of NT3, NGF, and GDNF in SCI, we used Western blotting analysis and real-time PCR to investigate the protein and gene expressions of NT3/NGF/GDNF in the spinal cord tissue. Eight weeks after transplantation, in spinal cord tissue, the protein expression of NGF in Groups 2, 3, and 4 was higher than that of Group $1(P<0.05)$. Among them, the protein expression of NGF was the highest in Group 4. Compared with the control group (Group 1), we found that the protein expression of GDNF was increased in Groups 2, 3, and $4(P<0.05)$. While, NT3 levels in the spinal cord were not different among each group (Figure 6A and B). In addition, the results of PCR showed that the gene expression levels of NGF and GDNF were consistent with the protein expression levels $(P<0.05)$. Similarly, the relative gene expression levels of NT3 in the spinal cord were still not different among each group (Figure 6C). These results show that after SCI, cell transplantation affected the protein and gene expressions of GDNF and NGF in spinal cord tissues. 

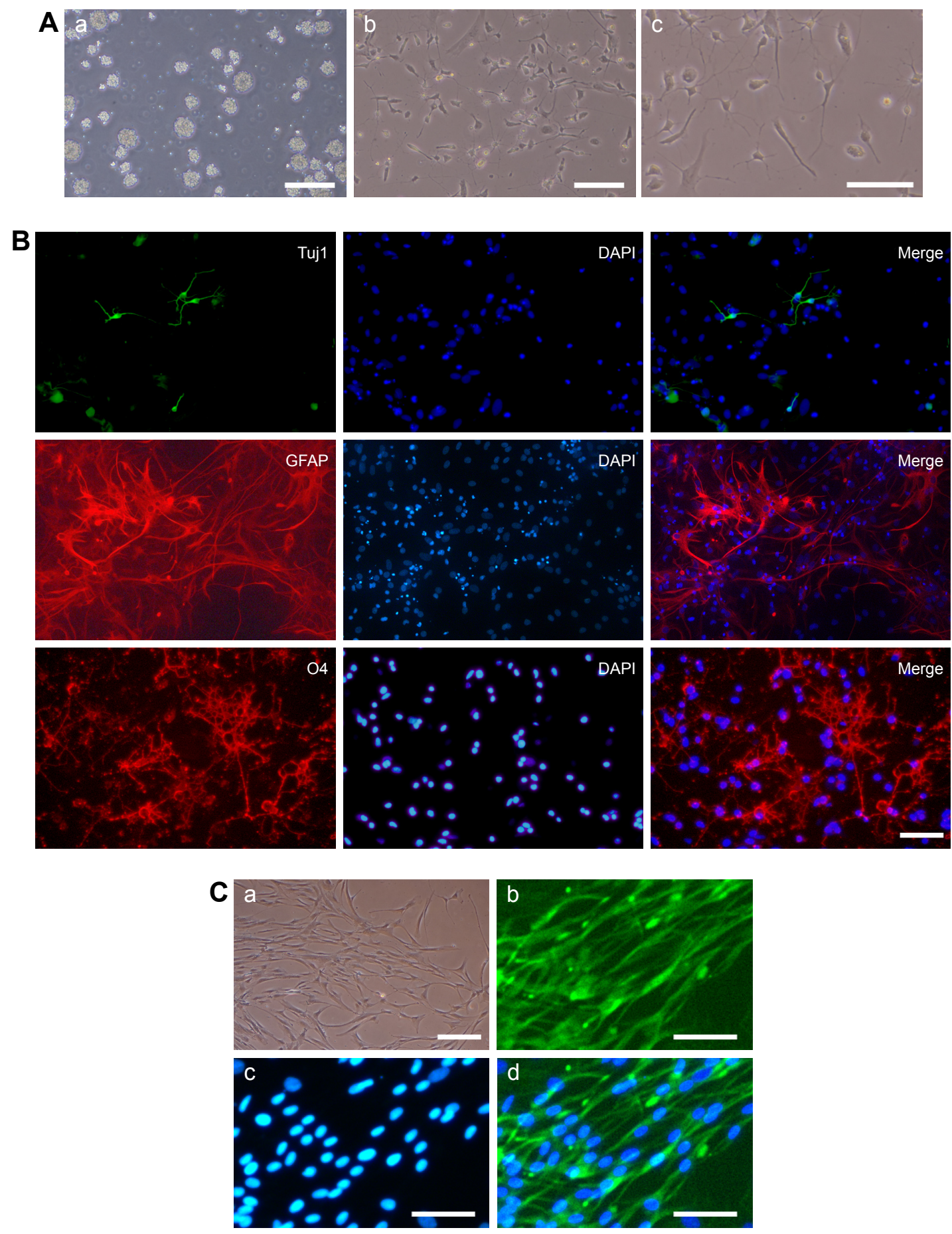

Figure 2 Preparation and characterization of iPSCs-NSCs and ASCs.

Notes: (A) The EBs (a) were cultured to allow the formation of self-organized neuroepithelium (b) that will give rise to iPSCs-NSCs (c). (B) Immunofluorescent staining images of Tuj I (green), GFAP (red), O4 (red), and DAPI (blue) of iPSCs-NSCs. (C) ASCs (a) express the peripheroneural markers SI00 (green) (b) and DAPI (blue) (c and d). Scale bar $=100 \mu \mathrm{m}$.

Abbreviations: ASCs, activated Schwann cells; DAPI, 4',6-Diamidino-2-Phenylindole; EBs, embryoid bodies; GFAP, glial fibrillary acidic protein; iPSCs-NSCs, induced pluripotent stem cells-derived neural stem cells; O4, oligodendrocyte marker O4; Tuj I, Class III $\beta$-tubulin.

\section{Discussion}

SCI is a common central nervous system disorder characterized by destruction or dysfunction of spinal cord caused by trauma or other causes. ${ }^{42-44} \mathrm{SCI}$ can cause a variety of complications that lead to irreversible loss of sensory and motor functions. Recently, the incidence of SCI showed a significant upward trend especially in developing countries, and this is a heavy burden for the 

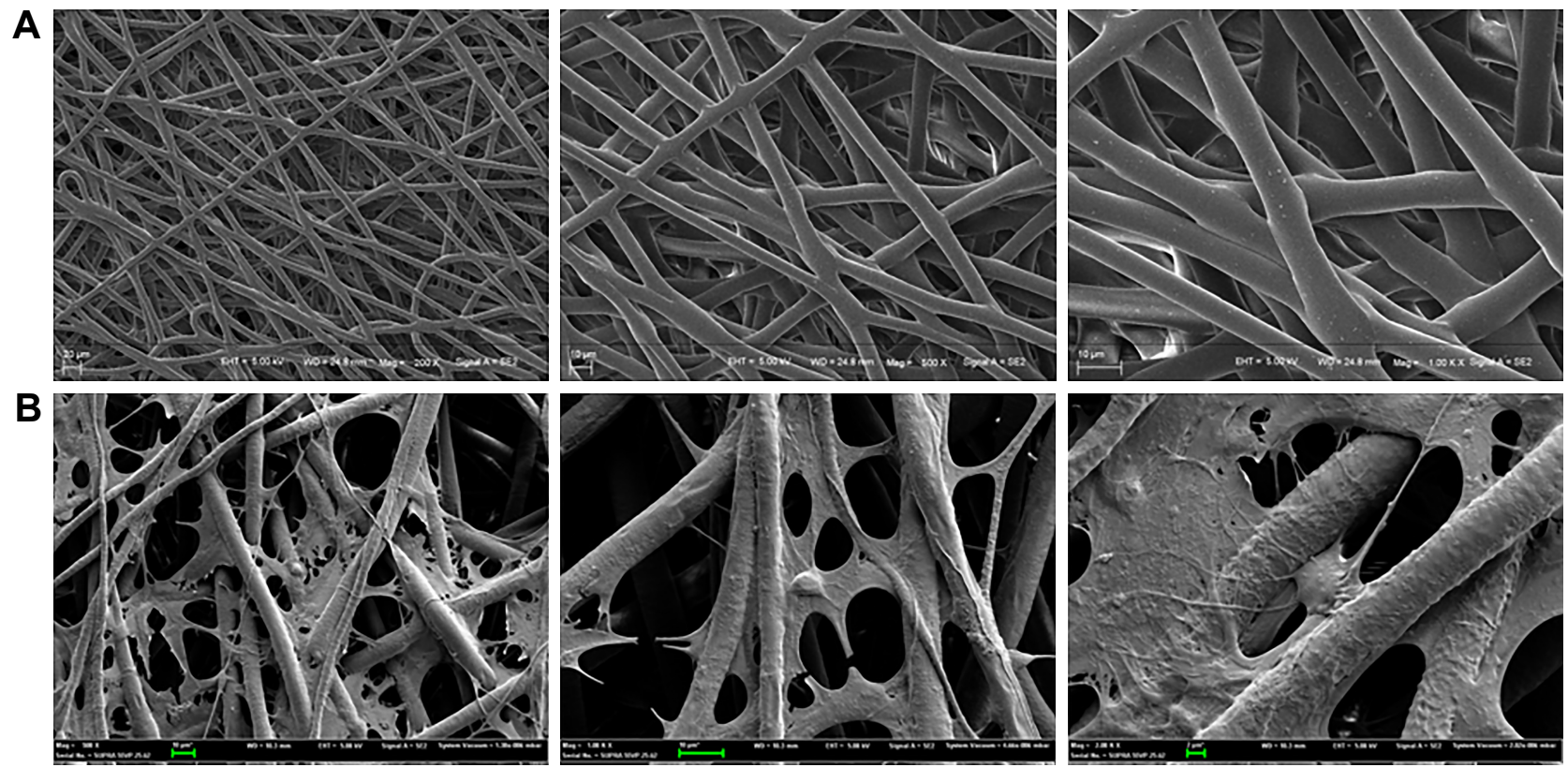

Figure 3 Preparation and characterization of tissue engineering scaffolds.

Notes: PCL with (A) or without ASCs and iPSCs-NSCs (B).

Abbreviations: ASCs, activated Schwann cells; iPSCs-NSCs, induced pluripotent stem cells-derived neural stem cells; PCL, polycaprolactone.

patients' family and society. ${ }^{45}$ While many strategies, such as surgery and drugs, failed to achieve a good therapeutic effect, the advent of stem cell therapy brings hope to the patients with SCI. In this study, hUCB-iPSCs were induced into NSCs as "seed cells" and was cocultured with ASCs on the PCL bioscaffold. After establishing the SCI model, the tissue engineering scaffolds were transplanted into the animals with SCI. Western blot, real-time PCR, immunohistochemical staining, and behavioral analyses were used to explore the effectiveness of repairing SCI, in order to provide new ideas and theoretical foundation for its clinical repair.

\section{A}

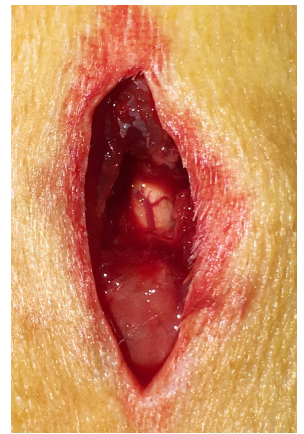

B

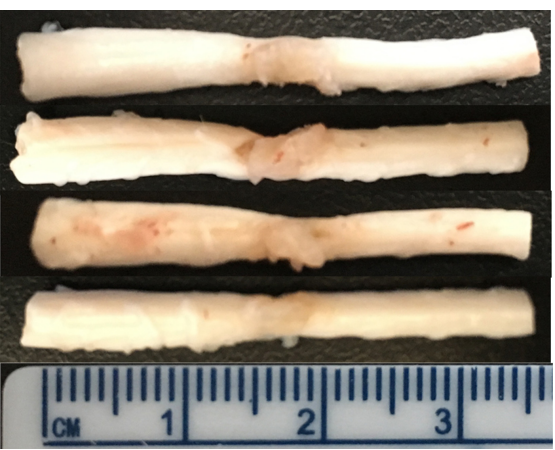

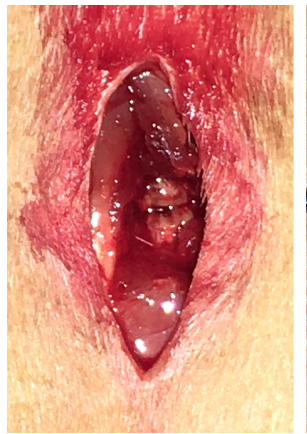

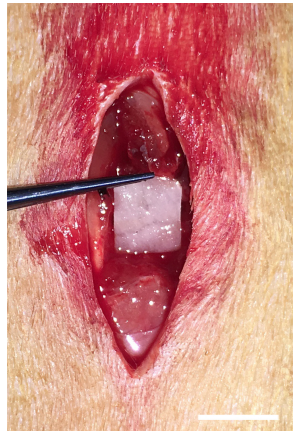

Group 1

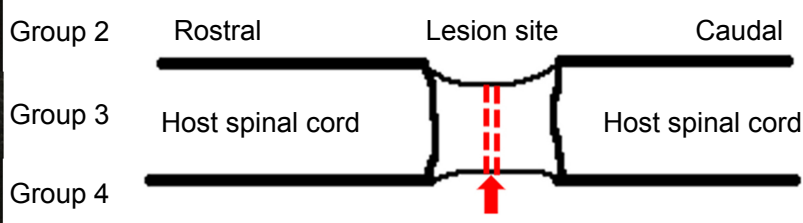

Paraffin section 

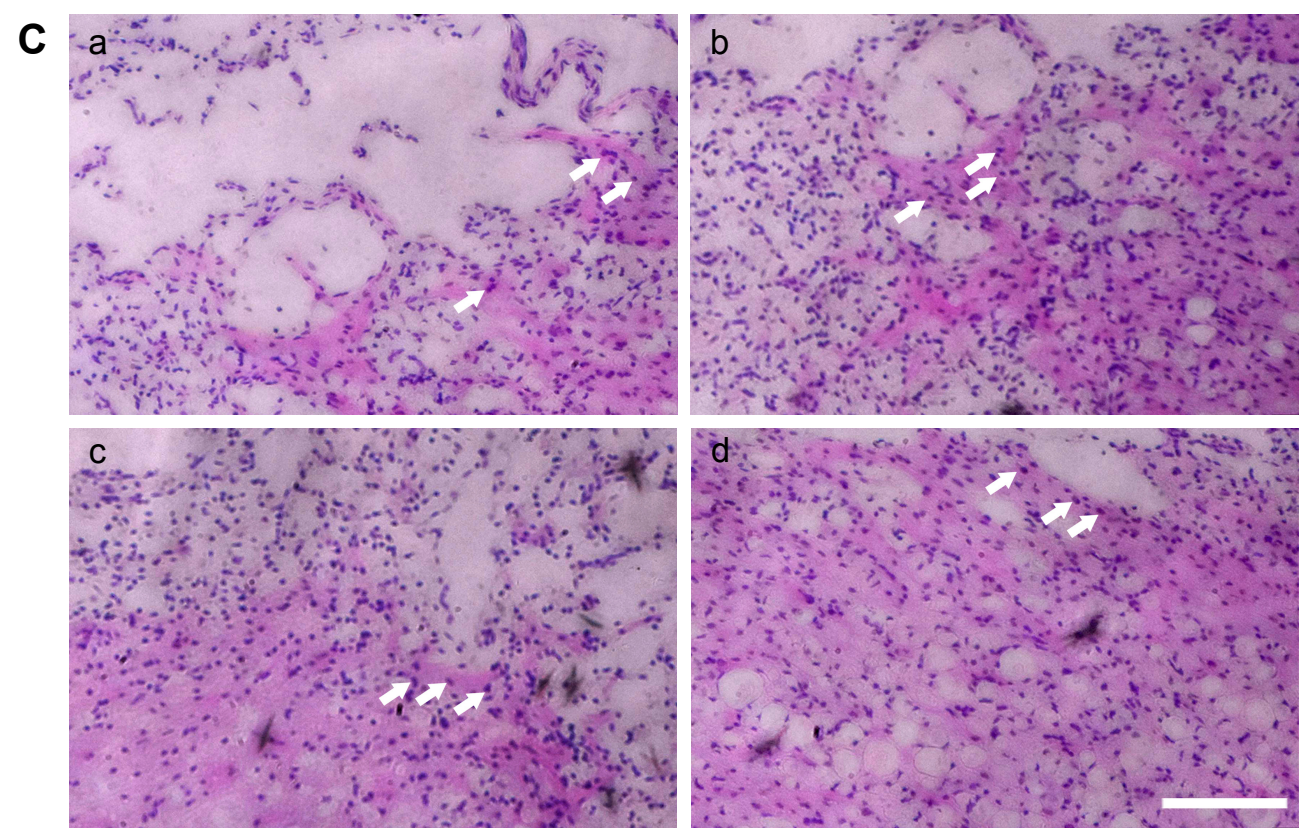

Figure 4 Axonal regeneration and remyelination of transplanted cells in injured spinal cord.

Notes: (A) Spinal cord transection and transplantation. Scale bar $=0.5 \mathrm{~cm}$. (B) Gross morphology and cavity formation of spinal cord tissue. (C) H\&E staining of Group I (a), Group 2 (b), Group 3 (c), and Group 4 (d). Arrows: infiltrated cells in spinal cord. Scale bar $=100 \mu \mathrm{m}$.

Abbreviation: H\&E, hematoxylin-eosin.

A number of studies have confirmed the efficacy of NSCs combined with SCs in the treatment of SCI. ${ }^{46,47}$ At present, it is illegal and unethical to extract human NSCs. Therefore, the purpose of this study was to explore a safer and more convenient way to obtain NSCs. IPSCs have unlimited self-renewal and pluripotent potential of embryonic stem cells, which allow them to differentiate into multiple types of mature cells in vitro. ${ }^{48}$ Moreover, it avoids many problems similar to embryonic stem cells, such as lack of cell origin, ethical, and allogeneic immune rejection. ${ }^{49}$ Takahashi and Yamanaka first used imitative transcription factors to successfully reprogram iPSCs from mouse fibroblasts in $2006 .{ }^{50} \mathrm{IPSCs}$ are gradually

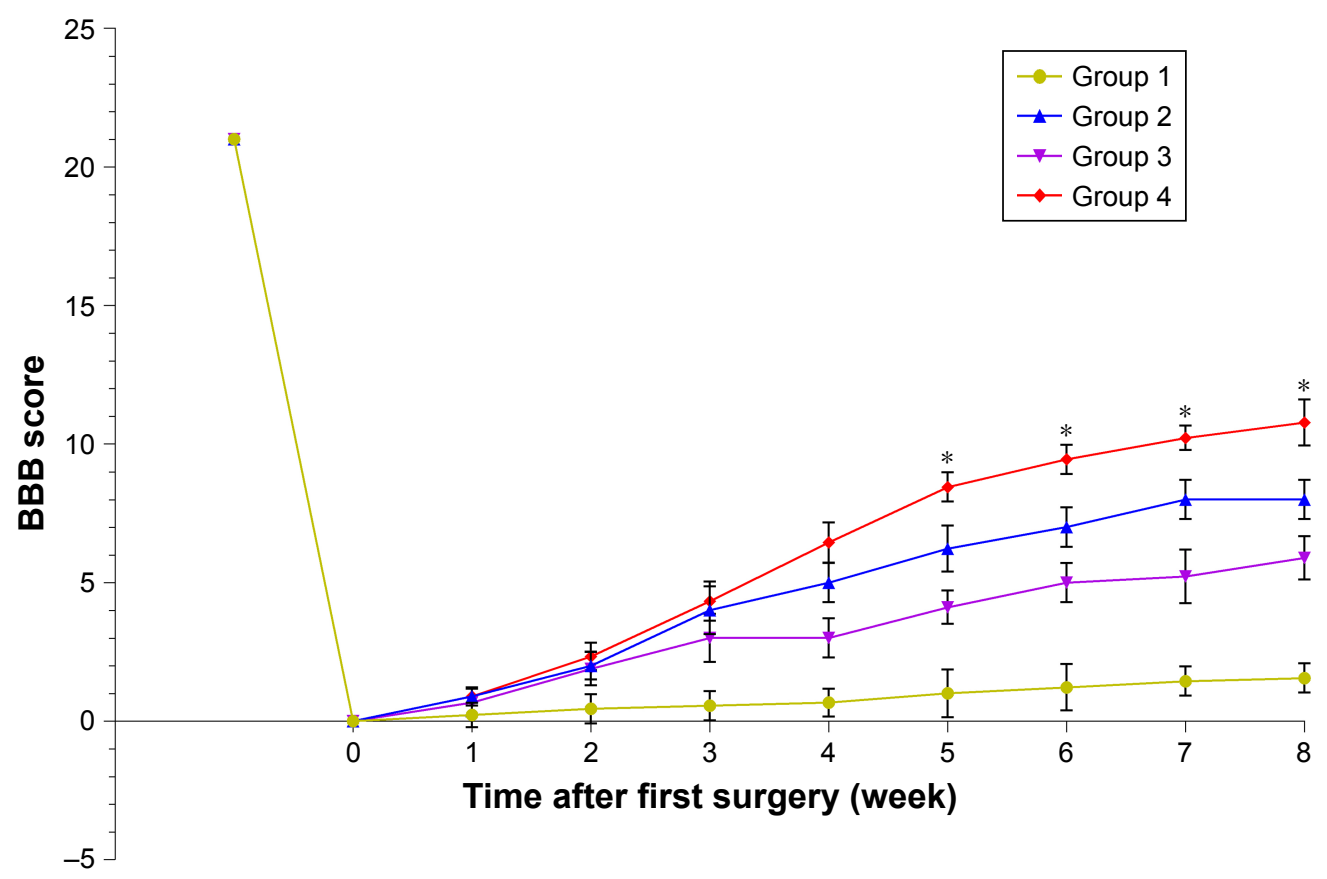

Figure 5 Functional analysis.

Notes: BBB scores of each treated group. $* P<0.05$.

Abbreviation: BBB, Basso, Beattie, and Bresnahan. 
A

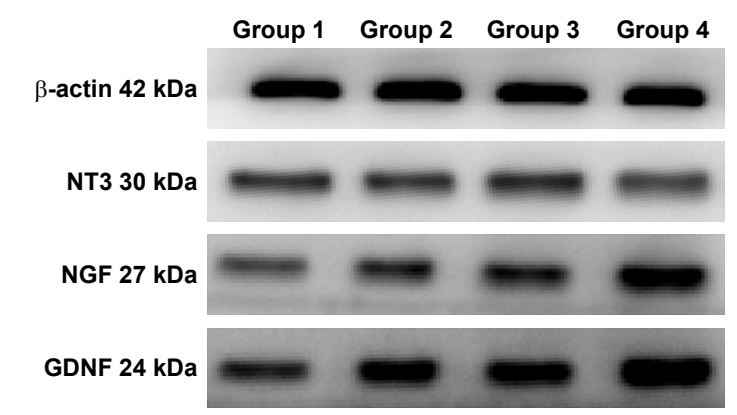

C

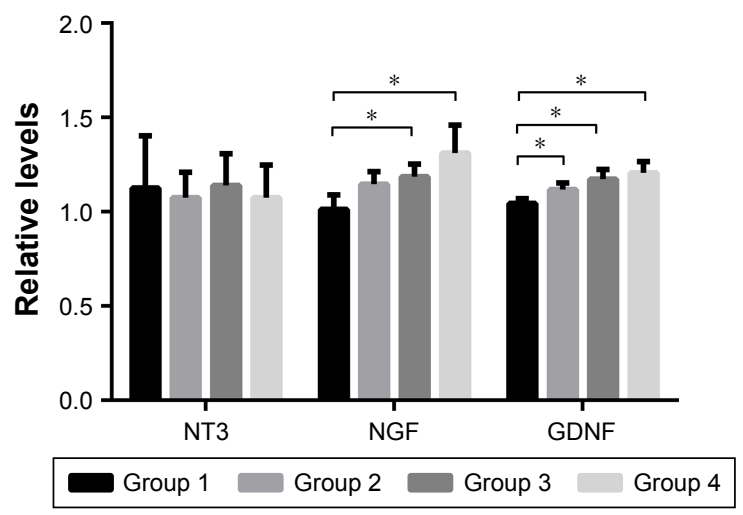

B
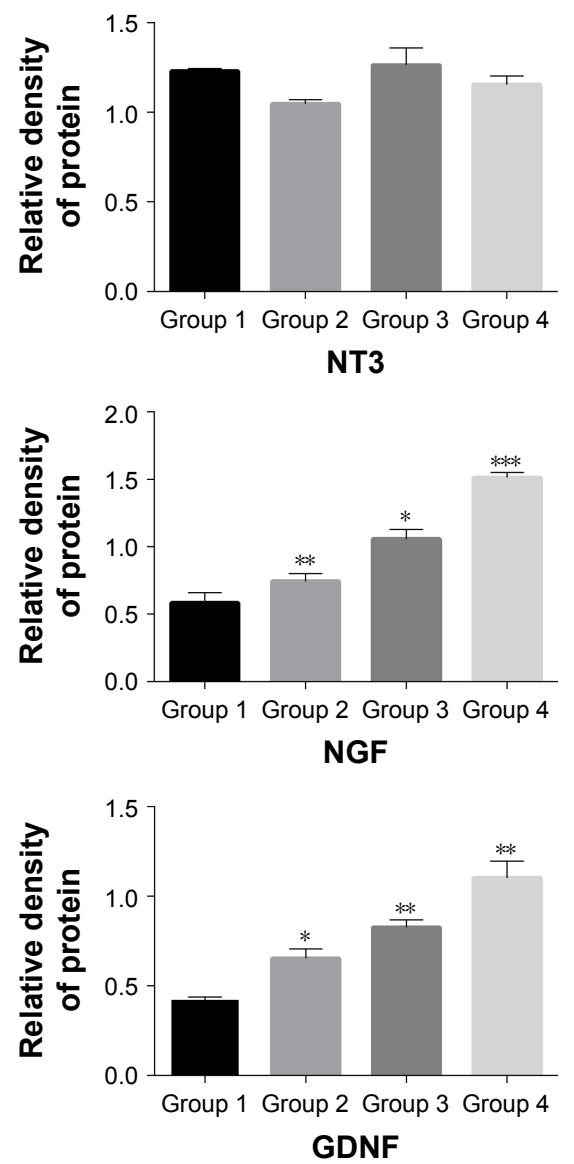

Figure 6 Analysis of NGF and neurotrophic factors.

Notes: The protein expression of NGF and GDNF (A) was increased in Group 2, Group 3, and Group 4 (B). The gene expression levels of NGF and GDNF were consistent with the protein expression levels $(\mathbf{C})$. $* P<0.05$, $* * P<0.0$ I, $* * * P<0.005$.

Abbreviations: GDNF, glial cell-derived neurotrophic factor; NGF, nerve growth factor; NT3, neurotrophin 3.

applied to disease models, drug screening, regenerative medicine, and other fields. ${ }^{51,52}$ Führmann et al have reported a peptide-modified, minimally invasive, injectable hydrogel containing hyaluronan and methylcellulose. ${ }^{53}$ They used the biomaterial to enhance the survival of human iPSCs-derived oligodendrocyte progenitor cells and cell differentiation. In their study, hydrogel attenuated teratoma formation by promoting cell differentiation. Similarly, there are many studies that suggest the use of $\gamma$-secretase inhibitor could promote neuronal differentiation and maturation in vitro in order to reduce teratoma formation after cell transplantation. ${ }^{54}$ However, unlike previous studies, our research use PCL electrospun fiber membrane for the preparation of tissue engineering scaffolds. In addition, many cells derived from iPSCs, such as cardiomyocytes, hepatocytes, and osteoblasts, should be used for further preclinical studies.

Biological materials are divided into two types: natural formation and artificial synthesis. They should have the following characteristics: degradable and biocompatible with a certain 3D structure. ${ }^{55}$ Among the many types of biodegradable materials, polylactic acid, chitosan, and gelatin are widely used. ${ }^{56}$ Most of the previous reports linked the PCL scaffolds with many diseases such as cardiovascular diseases and bone defects. Tardajos et al introduced chitosan as an antibacterial agent in a 3D printed PCL scaffold and used L929 fibroblasts to demonstrate the cell-adhesion and cell-viability capacity of the modified scaffolds. ${ }^{57}$ It is an innovative approach, and the antibacterial technology has been applied in this study in order to increase the safety and proliferation of cell cultures in scaffold. PCL, due its benign drug permeability, is often administrated in combination with other drugs to treat SCI. ${ }^{58}$ Previous studies have reported the use of dexamethasone acetate (DA)-loaded polymeric micelles to improve DA's water solubility, biocompatibility, and in reducing its side effects. ${ }^{59}$ In summary, the purpose of combining drugs or cells with biomaterials is to improve 
hindlimb functional recovery, decrease neuron loss and promote axon regeneration. This research strongly supports previous viewpoints and proposes that the use of PCL electrospun fiber membrane for SCI should be further explored.

In addition to seed cells and scaffolds, selected suitable growth factor could maximize the repair effect using tissue engineering method in SCI. Many NGFs and neurotrophic factors could not be ignored, including brain-derived neurotrophic factor, GDNF, NGF, NT3, and others, among which the most important are NGF, NT3, and GDNF. NGF was first discovered in 1950 and plays an important role in the survival, development, and maturation of neurons in the peripheral nervous system. ${ }^{60}$ In the spinal cord, the expression of NGF may induce hyperalgesia and robust spouting of nociceptive axons. ${ }^{61}$ GDNF is one of the important neurotrophic factors. GDNF and its receptors are widely expressed in the central nervous system in adults. ${ }^{62}$ Previous studies have demonstrated that in addition to the role of GDNF in axon regeneration, ${ }^{63,64}$ it can also promote the remodeling of spinal cord tissue by affecting the behavior of glial cells. The effect of the above factors on the repair of SCI is consistent with the results of our experiment, which found that the degree of spinal cord recovery and remodeling was closely related to NGF and GDNF. NT3 is a multifunctional gene and has an effect on maintaining the neuron and dopaminergic neuron differentiation. ${ }^{65}$ NT3 mRNA is highly expressed in the spinal cord in motor neurons. ${ }^{66}$ Several studies have shown that NT3 not only plays an important role in the development and differentiation of neurons, but also promotes the hindlimb functional recovery of motor function in rats with SCI. ${ }^{62,67,68}$ In our study, the NT3 levels in the spinal cord were unchanged after tissue engineering scaffolds transplantation, and these results may explain the slow recovery of hindlimb motor function in rats with SCI.

In this study, hUCB-iPSCs-derived NSCs combined with PCL electrospun fiber membrane were used for the first time to make tissue engineering scaffolds. The innovation of this study is to resolve ethical problems and utilize the good biocompatibility and degradability of the scaffold. Nevertheless, there are still some limitations in this study. First, the study did not continue to explore the cell's activity and proliferation ability on the PCL. Second, we did not observe whether there was tumor formation at the spinal cord after cell transplantation. Finally, the specific epigenetic mechanisms of cell transplantation for SCI should be further elucidated. Therefore, our next step will focus on epigenetic changes before and after cell induction and transplantation.
In addition, the therapeutic efficacy of other cells or scaffolds on SCI remains to be further explored.

In recent years, the repair of SCI by cell transplantation has become hotspots in the field of cell therapy, but there are significant differences in the effect and role of the repair of different cell combinations. Cell transplantation therapy can promote regeneration and remyelination of axons, replace apoptotic cells, thereby promoting the repair of spinal cord injuries, and creating favorable conditions for the recovery of sensory and motor functions. Therefore, the application of tissue engineering scaffold to promote nerve regeneration after SCI is the focus of our future research.

\section{Conclusion}

In this work, a novel tissue engineering scaffold was successfully synthesized. PCL electrospun fiber membrane loaded with iPSCs-NSCs and ASCs were prepared and evaluated for the treatment of SCI in vitro and in vivo. Cell-containing PCL scaffolds in this study have good biodegradability and biocompatibility. It plays a role in promoting tissue remodeling and secretion of neurotrophic factors. In addition, this tissue engineered scaffold could promote motor function recovery in a SCI model. Therefore, cell-containing PCL scaffolds maybe a clinically viable therapeutic strategy for SCI in the future.

\section{Acknowledgments}

This work was financially supported by the State Key Program of National Natural Science Foundation of China (81330042), State General Program National Natural Science Foundation of China (81371957), and International Cooperation Program of National Natural Science Foundation of China (81620108018).

\section{Disclosure}

The authors report no conflicts of interest in this work.

\section{References}

1. Niclis JC, Turner C, Durnall J, et al. Long-distance axonal growth and protracted functional maturation of neurons derived from human induced pluripotent stem cells after intracerebral transplantation. Stem Cells Transl Med. 2017;6(6):1547-1556.

2. Wang Q, He Y, Zhao Y, et al. A thermosensitive heparin-poloxamer hydrogel bridges aFGF to treat spinal cord injury. ACS Appl Mater Interfaces. 2017;9(8):6725-6745.

3. Li G, Shen F, Fan Z, et al. Dynasore improves motor function recovery via inhibition of neuronal apoptosis and astrocytic proliferation after spinal cord injury in rats. Mol Neurobiol. 2017;54(9):7471-7482.

4. Lu P, Woodruff G, Wang Y, et al. Long-distance axonal growth from human induced pluripotent stem cells after spinal cord injury. Neuron 2014;83(4):789-796 
5. Wang H, Liu C, Mei X, et al. Berberine attenuated pro-inflammatory factors and protect against neuronal damage via triggering oligodendrocyte autophagy in spinal cord injury. Oncotarget. 2017;8(58): 98312-98321.

6. Zhou Z, Liu C, Chen S, et al. Activation of the Nrf2/ARE signaling pathway by probucol contributes to inhibiting inflammation and neuronal apoptosis after spinal cord injury. Oncotarget. 2017;8(32): 52078-52093.

7. He QQ, Xiong LL, Liu F, et al. MicroRNA-127 targeting of mitoNEET inhibits neurite outgrowth, induces cell apoptosis and contributes to physiological dysfunction after spinal cord transection. Sci Rep. 2016; 6:35205.

8. Mao L, Gao W, Chen S, et al. Epothilone B impairs functional recovery after spinal cord injury by increasing secretion of macrophage colonystimulating factor. Cell Death Dis. 2017;8(11):e3162.

9. Nagashima K, Miwa T, Soumiya H, et al. Priming with FGF2 stimulates human dental pulp cells to promote axonal regeneration and locomotor function recovery after spinal cord injury. Sci Rep. 2017;7(1):13500.

10. Piltti KM, Funes GM, Avakian SN, et al. Increasing Human Neural Stem Cell Transplantation Dose Alters Oligodendroglial and Neuronal Differentiation after Spinal Cord Injury. Stem Cell Reports. 2017;8(6): 1534-1548.

11. Chen J, Wang Z, Zheng Z, et al. Neuron and microglia/macrophagederived FGF10 activate neuronal FGFR2/PI3K/Akt signaling and inhibit microglia/macrophages TLR4/NF-кB-dependent neuroinflammation to improve functional recovery after spinal cord injury. Cell Death Dis. 2017;8(10):e3090

12. Lee JY, Kang SR, Yune TY. Fluoxetine prevents oligodendrocyte cell death by inhibiting microglia activation after spinal cord injury. J Neurotrauma. 2015;32(9):633-644.

13. Springer JE, Visavadiya NP, Sullivan PG, Hall ED. Post-Injury Treatment with NIM811 Promotes Recovery of Function in Adult Female Rats after Spinal Cord Contusion: A Dose-Response Study. J Neurotrauma. 2018;35(3):492-499.

14. Malikmammadov E, Tanir TE, Kiziltay A, Hasirci V, Hasirci N. PCL and PCL-based materials in biomedical applications. J Biomater Sci Polym Ed. 2018;29(7-9):863-893.

15. Nicaise AM, Banda E, Guzzo RM, et al. iPS-derived neural progenitor cells from PPMS patients reveal defect in myelin injury response. Exp Neurol. 2017;288:114-121.

16. Sampaziotis F, de Brito MC, Madrigal P, et al. Cholangiocytes derived from human induced pluripotent stem cells for disease modeling and drug validation. Nat Biotechnol. 2015;33(8):845-852.

17. Kawamata S, Kanemura H, Sakai N, Takahashi M, Go MJ, Mj G. Design of a Tumorigenicity Test for Induced Pluripotent Stem Cell (iPSC)-Derived Cell Products. J Clin Med. 2015;4(1):159-171.

18. Ovchinnikov DA, Sun J, Wolvetang EJ. Generation of Footprint-Free Induced Pluripotent Stem Cells from Human Fibroblasts Using Episomal Plasmid Vectors. Methods Mol Biol. 2015;1330:37-45.

19. Takahashi K, Tanabe K, Ohnuki M, et al. Induction of pluripotent stem cells from adult human fibroblasts by defined factors. Cell. 2007; 131(5):861-872.

20. Cyranoski D. Japanese woman is first recipient of next-generation stem cells. Nature. 2014. Epub 2014 Sep 12.

21. Jessen KR, Mirsky R, Lloyd AC. Schwann cells: development and role in nerve repair. Cold Spring Harb Perspect Biol. 2015;7(7): a020487.

22. Feltri ML, Poitelon Y, Previtali SC. How Schwann cells sort axons: new concepts. Neuroscientist. 2016;22(3):252-265.

23. Zhou XH, Ning GZ, Feng SQ, et al. Transplantation of autologous activated Schwann cells in the treatment of spinal cord injury: six cases, more than five years of follow-up. Cell Transplant. 2012;21 Suppl 1(Suppl 1): 39-47.

24. Hill CE, Moon LD, Wood PM, Bunge MB. Labeled Schwann cell transplantation: cell loss, host Schwann cell replacement, and strategies to enhance survival. Glia. 2006;53(3):338-343.
25. Marcol W, Ślusarczyk W, Larysz-Brysz M, et al. Grafted activated Schwann cells support survival of injured rat spinal cord white matter. World Neurosurg. 2015;84(2):511-519.

26. Saadai P, Wang A, Nout YS, et al. Human induced pluripotent stem cellderived neural crest stem cells integrate into the injured spinal cord in the fetal lamb model of myelomeningocele. J Pediatr Surg. 2013;48(1): $158-163$.

27. Romanyuk N, Amemori T, Turnovcova K, et al. Beneficial effect of human induced pluripotent stem cell-derived neural precursors in spinal cord injury repair. Cell Transplant. 2015;24(9):1781-1797.

28. Uezono N, Zhu Y, Fujimoto Y, et al. Prior treatment with anti-high mobility group box-1 antibody boosts human neural stem cell transplantation-mediated functional recovery after spinal cord injury. Stem Cells. 2018;36(5):737-750.

29. Novikova LN, Kolar MK, Kingham PJ, et al. Trimethylene carbonatecaprolactone conduit with poly-p-dioxanone microfilaments to promote regeneration after spinal cord injury. Acta Biomater. 2018;66: 177-191.

30. Rumbo C, Tamayo-Ramos JA, Caso MF, et al. Colonization of electrospun polycaprolactone fibers by relevant pathogenic bacterial strains. ACS Appl Mater Interfaces. 2018;10(14):11467-11473.

31. Kularatne RN, Washington KE, Bulumulla C, et al. Histone deacetyinhibitor (HDACi) conjugated polycaprolactone for combination cancer therapy. Biomacromolecules. 2018;19(3):1082-1089.

32. Sharifi F, Patel BB, Dzuilko AK, Montazami R, Sakaguchi DS, Hashemi N. Polycaprolactone microfibrous scaffolds to navigate neural stem cells. Biomacromolecules. 2016;17(10):3287-3297.

33. Joshi MK, Tiwari AP, Pant HR, et al. In situ generation of cellulose nanocrystals in polycaprolactone nanofibers: effects on crystallinity, mechanical strength, biocompatibility, and biomimetic mineralization. ACS Appl Mater Interfaces. 2015;7(35):19672-19683.

34. Fan B, Zhou X, Wang L, et al. In vitro study of neural stem cells and activated Schwann cells cocultured on electrospinning polycaprolactone scaffolds. Journal of Neurorestoratology. 2017;5:155-165.

35. Coelho de Oliveira VC, Silva dos Santos D, Vairo L, et al. Hair follicle-derived mesenchymal cells support undifferentiated growth of embryonic stem cells. Exp Ther Med. 2017;13(5):1779-1788.

36. Han X, Yu L, Ren J, et al. Efficient and fast differentiation of human neural stem cells from human embryonic stem cells for cell therapy. Stem Cells Int. 2017;2017:9405204.

37. Woodhoo A, Alonso MB, Droggiti A, et al. Notch controls embryonic Schwann cell differentiation, postnatal myelination and adult plasticity. Nat Neurosci. 2009;12(7):839-847.

38. Liu C, Huang Y, Pang M, et al. Tissue-engineered regeneration of completely transected spinal cord using induced neural stem cells and gelatin-electrospun poly (lactide-co-glycolide)/polyethylene glycol scaffolds. PLoS One. 2015;10(3):e0117709.

39. Fan H, Chen K, Duan L, Wang YZ, Ju G. Beneficial effects of early hemostasis on spinal cord injury in the rat. Spinal Cord. 2016;54(11): 924-932.

40. Basso DM, Beattie MS, Bresnahan JC. A sensitive and reliable locomotor rating scale for open field testing in rats. J Neurotrauma. 1995; 12(1):1-21

41. Zhou XH, Lin W, Ren YM, et al. Comparison of DNA Methylation in Schwann Cells before and after Peripheral Nerve Injury in Rats. Biomed Res Int. 2017;2017:5393268.

42. Han D, Yu Z, Liu W, et al. Plasma Hemopexin ameliorates murine spinal cord injury by switching microglia from the M1 state to the M2 state. Cell Death Dis. 2018;9(2):181.

43. Gwak S-J, Macks C, Bae S, Cecil N, Lee JS. Physicochemical stability and transfection efficiency of cationic amphiphilic copolymer/pDNA polyplexes for spinal cord injury repair. Sci Rep. 2017;7(1):11247.

44. Mothe AJ, Tassew NG, Shabanzadeh AP, et al. RGMa inhibition with human monoclonal antibodies promotes regeneration, plasticity and repair, and attenuates neuropathic pain after spinal cord injury. Sci Rep. 2017;7(1):10529 
45. Jazayeri SB, Beygi S, Shokraneh F, Hagen EM, Rahimi-Movaghar V. Incidence of traumatic spinal cord injury worldwide: a systematic review. Eur Spine J. 2015;24(5):905-918.

46. Wang D, Liang J, Zhang J, Liu S, Sun W. Mild hypothermia combined with a scaffold of NgR-silenced neural stem cells/Schwann cells to treat spinal cord injury. Neural Regen Res. 2014;9(24):2189-2196.

47. Lai BQ, Wang JM, Ling EA, Wu JL, Zeng YS. Graft of a tissueengineered neural scaffold serves as a promising strategy to restore myelination after rat spinal cord transection. Stem Cells Dev. 2014 23(8):910-921.

48. Hoshina A, Kawamoto T, Sueta S-I, et al. Development of new method to enrich human iPSC-derived renal progenitors using cell surface markers. Sci Rep. 2018;8(1):6375.

49. Yoshida Y, Yamanaka S. Induced pluripotent stem cells 10 years later: for cardiac applications. Circ Res. 2017;120(12):1958-1968.

50. Takahashi K, Yamanaka S. Induction of pluripotent stem cells from mouse embryonic and adult fibroblast cultures by defined factors. Cell. 2006;126(4):663-676.

51. Bhartiya D, Shaikh A, Anand S, et al. Endogenous, very small embryonic-like stem cells: critical review, therapeutic potential and a look ahead. Hum Reprod Update. 2016;23(1):41-76.

52. Karakikes I, Termglinchan V, Cepeda DA, et al. A comprehensive TALEN-based knockout library for generating human-induced pluripotent stem cell-based models for cardiovascular diseases. Circ Res. 2017;120(10):1561-1571.

53. Führmann T, Tam RY, Ballarin B, et al. Injectable hydrogel promotes early survival of induced pluripotent stem cell-derived oligodendrocytes and attenuates longterm teratoma formation in a spinal cord injury model. Biomaterials. 2016;83:23-36.

54. Okubo T, Iwanami A, Kohyama J, et al. Pretreatment with a $\gamma$-secretase inhibitor prevents tumor-like overgrowth in human iPSC-derived transplants for spinal cord injury. Stem Cell Reports. 2016;7(4): 649-663.

55. Teuschl A, Heimel $P$, Nürnberger $S$, van Griensven M, Redl H, Nau T. Novel silk fiber-based scaffold for regeneration of the anterior cruciate ligament: histological results from a study in sheep. Am J Sports Med. 2016;44(6):1547-1557.

56. Gai M, Frueh J, Kudryavtseva VL, Yashchenok AM, Sukhorukov GB. Polylactic acid sealed polyelectrolyte multilayer microchambers for entrapment of salts and small hydrophilic molecules precipitates. ACS Appl Mater Interfaces. 2017;9(19):16536-16545.
57. Tardajos MG, Cama G, Dash M, et al. Chitosan functionalized poly$\varepsilon$-caprolactone electrospun fibers and $3 \mathrm{D}$ printed scaffolds as antibacterial materials for tissue engineering applications. Carbohydr Polym. 2018;191:127-135.

58. Wang J, Wang J, Lu P, et al. Local delivery of FTY720 in PCL membrane improves SCI functional recovery by reducing reactive astrogliosis. Biomaterials. 2015;62:76-87.

59. Wang Y, Wu M, Gu L, et al. Effective improvement of the neuroprotective activity after spinal cord injury by synergistic effect of glucocorticoid with biodegradable amphipathic nanomicelles. Drug Deliv. 2017;24(1):391-401.

60. Levi-Montalcini R, Hamburger V. Selective growth stimulating effects of mouse sarcoma on the sensory and sympathetic nervous system of the chick embryo. J Exp Zool. 1951;116(2):321-361.

61. Gwak YS, Nam TS, Paik KS, Hulsebosch CE, Leem JW. Attenuation of mechanical hyperalgesia following spinal cord injury by administration of antibodies to nerve growth factor in the rat. Neurosci Lett. 2003;336(2):117-120.

62. Awad BI, Carmody MA, Steinmetz MP. Potential role of growth factors in the management of spinal cord injury. World Neurosurg. 2015;83(1):120-131.

63. Iannotti C, Li H, Yan P, Lu X, Wirthlin L, Xu XM, Xm X. Glial cell line-derived neurotrophic factor-enriched bridging transplants promote propriospinal axonal regeneration and enhance myelination after spinal cord injury. Exp Neurol. 2003;183(2):379-393.

64. Mills CD, Allchorne AJ, Griffin RS, Woolf CJ, Costigan M. GDNF selectively promotes regeneration of injury-primed sensory neurons in the lesioned spinal cord. Mol Cell Neurosci. 2007;36(2):185-194.

65. Ji WC, Zhang XW, Qiu YS. Selected suitable seed cell, scaffold and growth factor could maximize the repair effect using tissue engineering method in spinal cord injury. World J Exp Med. 2016;6(3):58-62.

66. Keefe KM, Sheikh IS, Smith GM. Targeting Neurotrophins to Specific Populations of Neurons: NGF, BDNF, and NT-3 and Their Relevance for Treatment of Spinal Cord Injury. Int J Mol Sci. 2017;18(3):548.

67. Daviaud N, Garbayo E, Schiller PC, Perez-Pinzon M, Montero-Menei CN. Organotypic cultures as tools for optimizing central nervous system cell therapies. Exp Neurol. 2013;248:429-440.

68. Park SS, Byeon YE, Ryu HH, et al. Comparison of canine umbilical cord blood-derived mesenchymal stem cell transplantation times: involvement of astrogliosis, inflammation, intracellular actin cytoskeleton pathways, and neurotrophin-3. Cell Transplant. 2011;20(11-12): $1867-1880$.
International Journal of Nanomedicine

\section{Publish your work in this journal}

The International Journal of Nanomedicine is an international, peerreviewed journal focusing on the application of nanotechnology in diagnostics, therapeutics, and drug delivery systems throughout the biomedical field. This journal is indexed on PubMed Central, MedLine, CAS, SciSearch $®$, Current Contents $\AA /$ Clinical Medicine,

\section{Dovepress}

Journal Citation Reports/Science Edition, EMBase, Scopus and the Elsevier Bibliographic databases. The manuscript management system is completely online and includes a very quick and fair peer-review system, which is all easy to use. Visit http://www.dovepress.com/ testimonials.php to read real quotes from published authors. 